\title{
Intention to Read News on the Internet: A Brazilian Public Analysis
}

\author{
Andrade, Renato Fonseca Alves de ${ }^{1}$, Lima, Carlos Roberto Camelo ${ }^{1} \&$ Pereira, Fernando Antonio de Melo $^{2}$ \\ ${ }^{1}$ Production engineering, Universidade Metodista de Piracicaba, São Paulo, Brazil \\ ${ }^{2}$ Management, Universidade de São Paulo FEA/USP, São Paulo, Brazil \\ Correspondence: Fernando Antonio de Melo, Rua Joaquim Eduardo de Farias, 209, Ed. Sunset, B1. A, Ap. 1301. \\ Ponta Negra, Natal/RN, Brazil. Tel: 55-119-4843-5185 / 55-849-954-5953. E-mail: fernandopcmm@usp.br
}

Received: November 18, 2014

Accepted: December 6, 2014

Online Published: January 25, 2015

doi:10.5539/ibr.v8n2p51

URL: http://dx.doi.org/10.5539/ibr.v8n2p51

\begin{abstract}
The main objective of the research was to identify factors related to the usage of the Internet service of readings, assessed by Brazilian readers and evaluate the intended use of readers based on the factors we have found. The methodological procedures involved conducted an online survey research, with the formation of a database formed by the Brazilian public that uses the Internet. Multivariate analysis techniques, such as exploratory factor analysis and logistic regression analysis were used. In the perception of the readers, there are three dimensions that differentiate the innovative user from the late user regarding the use of the web to read news, namely: the practicality of the platform, knowledge of technology and the external influence. From the results it can be concluded that the innovative public drives the latent growth of reading newspapers on the Internet and those who do not intend to use in the future may become users following the evolution and popularization of digital media
\end{abstract}

Keywords: digital media management, innovation diffusion theory, logistic regression

\section{Introduction}

The Based on the reports by Circulation Verification Institute (CVI), Brazilian Institute of Public Opinion and Statistics (IBOPE), National Association of Newspapers (ANJ) and Newspaper Association of America (NAA), the Internet platform a few years ago, has been one of the main centers of discussion in regards to the media, since access to news has changed compared to traditional media. New media enables interactivity and non-linear navigation. The content is found abundantly and updated in real time (Orihuela, 2003).

This current phenomenon, the media convergence, represents a change in how they understand the relationship with the media, which alters the way the communication is effective. If the digital revolution paradigm assumed that new media replace old ones, the emerging convergence paradigm assumes that old and new media will interact in an increasingly complex ways (Jenkins, 2008). Thus, the media convergence alters the relationship between existing technologies, industries, markets, genres and audiences (Gimpel \& Westerman, 2012).

Among the various conceptualizations of Internet, a simple and an easy way to understand it, is that it is a collection of connected networks, becoming the largest network of computers worldwide use (Cronin, 1996). Even after almost twenty years, the concepts and Ozcubucku Gascoyne (1997) are still valid, since, as the authors claimed, the use of the Internet has changed the focus of the relationship between companies and their users by breaking geographical boundaries, reducing costs and the opening of the application for business and communication infrastructure. The online and free dissemination of the content was not perceived by publishers as a threat to traditional print media business (Peng; Tham, \& Xiaoming, 1999). Currently, this threat is widely discussed in the news media and in academic research (Gaskins \& Jerit, 2013). From data IBOPE (2012) and the NAA (2012), it appears that Internet users started to use the network on a daily basis, which led to increase average access time to the Internet as well as the amount of users. The use of the Internet access for the content produced by writers of newspapers has a considerable index as the number of users according to the CVI in 2012.

Prior research suggests the preference of different audiences for online news at the expense of the printed news (Olmsted, Rim, \& Zerba, 2013; Chyi \& Lee, 2013; Jung, Lin, \& Kim, 2012). From data IBOPE (2012) and the NAA (2012) it appears that Internet users started to use the network on a daily basis, which led to increase the average access time to the Internet as well as the amount of users. In Kaufhold's research (2010), despite the 
preference for online news, there was no reduction in the use of printed newspapers.

Based on Jenkins (2008), the convergence of formats on the Internet is not limited to the content and may influence, commonly, in the way it is presented. Thus, different functions are synergistically platform on the Internet.

As a key part of the strategy for the business model of print media in the network business, one must consider the users' perception. "The innovativeness is measured by the period in which a person decides to adopt an innovation" (Rogers, 1983, p. 247). Combining innovation strategies and providing usability experiences based on innovation and influences a next innovation, as suggested by the Innovation Diffusion Theory (IDT) of Rogers (2003). Hennschen and Andersen (2012, p. 13) state that "one of the mature parts of the book of Rogers (1995) is the description of how to develop an idea where he emphasizes the importance of communication channels".

In this context, this study aims to identify factors related to the use of the Internet readings services and evaluate the intended use of readers based on factors found, according to the Brazilian public perception. To achieve this goal, factors that explain the intention to read news on the Internet will be identified, and analyzing factors that contribute to differentiate the innovative readers of late readers, dividing audiences between those who intend to keep reading news on the Internet, from the ones who has no intention.

The context of this work is a setting of changes occurring due to the impact of the Internet, which affect the business involving the written media and, consequently, the newspapers. These changes will be considered from the point of view of economic theory, thereby enabling the identification of the main factors that can influence the strategic decisions of the companies involved. Furthermore, the work context involves a socially paper industry. The media influences public awareness through news agenda, selecting what is published, how often and through certain frames and angles (Dotson et al., 2012; Franklin, 2013).

This research builds upon the conceptual foundations of the IDT is also used information contained in the databases of the companies studied, granted by the IVC and websites performance measures, and questionnaires for newspaper readers to understand how the management and the transition occurs the traditional model to digital. This study does not involve evaluation of content of online news, as only evaluates the perception of use of readers.

\section{Changes in the Newspapers Marketing}

The impact of the Internet in the media has been the subject of debates and studies increasingly frequent in recent decades. This research addresses the issue through two theories explaining the following phenomena: (I) penetration and usability of the Internet, which impact and generate opportunities for newspapers Innovation Diffusion Theory. (II) the competitive advantage of printed newspapers on proven indicators of hearing these vehicles web digital platform, which is based on studies of the Resource-Based View.

It is clear that there is a greater penetration and a growing awareness of how technology is adopted as an innovation (Means et al., 1993; Rogers, 995; Surry, 1997; Jacobsen, 1998; Carr Junior, 2001; Rogers, 2003). The emergence of the Internet has become a source of further research especially on its role as a catalyst for business change.

Over the past 10 years, the online newspaper websites comments were rare, being restricted to anonymous comments, journalists, photographers and other professionals related to the area (Nielsen, 2012). Currently, the market for Internet access has already become representative for the Brazilian and world economy. People are increasingly using for several reasons: entertainment, shopping, payments and researches, among others.

In the area of technological innovation, IDT has been used to study the factors that may facilitate or impede the adoption of an innovation (Rogers, 1995; Rogers, 2003; Black, 2001). The IDT has also been applied in various technology related areas, including adoption of mobile banking (Jabri \& Sohail, 2012; Lee \& Chung, 2009), satisfaction and trust in online payments (Au \& Kauffman, 2008; Chen, 2008) and several issues related to the newspaper market, as the jurisdictional protectionism online (Chang, Southwell, \& Hong, 2010), supported by comments online (Nielsen, 2012), digital journalism (Aitamurto \& Lewis, 2012), the efficient diffusion of costs in the field of communication (Hennschen \& Andersen, 2012), among others.

The Table below shows recent researches on the subject, which in essence address the transition from analog to digital model, positioning of managers beyond changes in market determinants of consumption and seek to understand the relationship between the online and printed versions are presented newspapers. 
Table 1. Theoretical aspects and methods of studies on digital media management

\begin{tabular}{ll}
\hline Reference & \multicolumn{1}{c}{ Topic } \\
\hline Chung, Nam and Stefanone (2012) & $\begin{array}{l}\text { Exploring the credibility of online news: the relative influence of traditional and } \\
\text { technological factors }\end{array}$ \\
Hennschen and Andersen (2012) & $\begin{array}{l}\text { A guide to a effective innovation diffusion of cost focus in the area of communication } \\
\text { Adoption of mobile news for young adults: examining perceptions of roles, news } \\
\text { Olmsted, Rim and Zerba (2013) }\end{array}$ \\
consumption and media usage \\
Thyi and Lee (2013) & $\begin{array}{l}\text { intention to pay } \\
\text { Gaskins and Jerit (2013) }\end{array}$ \\
Nielsen (2012) & $\begin{array}{l}\text { Newspaper journalists : support online reviews } \\
\text { Cacciatore et al. (2012) }\end{array}$ \\
Eung, Lin and Kim (2012) & $\begin{array}{l}\text { The dynamic relationship between the use of the Internet and other media for teens from } \\
\text { East Asian }\end{array}$ \\
Aitamurto and Lewis (2012) & $\begin{array}{l}\text { Open innovation in digital journalism : examining the impact of open APIs in four } \\
\text { organizations }\end{array}$ \\
\hline
\end{tabular}

\section{Method}

\subsection{Participants and Sample Procedures}

The study is characterized as being descriptive, quantitative approach and a cross section (Gil, 2002; Samara \& Barros, 2002). The study adopted an approach of collecting primary quantitative data through an online survey. The population is composed by Brazilian news readers on the Internet. The questionnaire was based on IDT (Rogers, 1995), with provision in the five constructs that define the rate of diffusion of innovation. The focus of the survey instrument is to understand the perceptions of usability and trends in the use of online media. After analyzing this information, you can have a greater mastery of the subject, from the perspectives of the customer profile.

The questionnaires were sent by email, through a presentation text and a hyperlink that directed to the questionnaire, hosted by GoogleDrive. The average response time was five (5) minutes. All questions were compulsory, preventing the identification of lost data. The questionnaire was administered from March to April 2014.

\subsection{Sample Size and Statistical Power}

The sampling design is a single phase, with random selection and probability, i.e., each individual in the population has an equal probability of being selected and the results must admit inferences about the population. The sample composition was analyzed a priori and a posteriori statistical power. Mayr et al. (2007) explains that the statistical power is essential for the evaluation of statistical decisions, as well as for the design of the data. Thus, the $\mathrm{G}^{*}$ Power 3.0 software was used to verify the adequacy of the sample.

The sample consists of 159 observations. Hair et al. (2011) state that a sample to be considered appropriate should have statistical power above 0.8 , fixing a priori effect size of 0.15 and the predictor variables. For the use of statistical procedures in the study, a F post-hoc test, which verifies the statistical power of the used samples. The results show that the statistical power to readers of the layer was 0.98 . With these results, the research sample exceeds the minimum required, maximizing the statistical power.

\subsection{Technics and Data Treatment}

Multivariate data analysis includes all the statistical techniques that simultaneously analyze measurements on objects of investigation. For this, two multivariate techniques are used in this study, include: Exploratory Factor Analysis (EFA) and logistic regression (LR) or Binary Regression.

To use such techniques, the first decision to be made by the researcher is the sample size and adaptation to techniques to be used. Hair et al. (2011), Corrar, Paulo and Dias (2009) and Favero et al. (2009) suggested that researchers plan a study of statistical power 0.80 at significance level desired, and the obtained statistical power increases in proportion to an increase of the sample. 
Thus, the sample calculations described above meet the premise of the techniques. The goal of RL is to use analysis of the independent variables (constructs), whose values are known to predict factors that differentiate the sample based on the dependent variable (Corrar, Paulo, \& Dias, 2009; HAIR et al., 2011). The software used is the Statistical Package for Social Sciences (SPSS v. 21.). The software also helps the treatment process of the database and generates descriptive statistics of the variables measured.

A pre-test questionnaire for the reader in the process of validation of the scale was conducted. The pre-test consisted of the collection of 30 observations from the sending of the questionnaire for the reader to researchers at the master's and doctoral familiarity with the concepts of IDT and fall in public: newsreader Internet.

Data were subjected to analysis of graphics of normal probability (NPP) to the Kolmogorov-Smirnov test and the Shapiro-Wilk normality test to the assessment of outliers using the Box-Plot graphics for each variable. Outlying observations were identified after the removal of outliers, and the database showed no violations of normality sufferable.

\subsection{Sample Profile}

In the descriptive analysis, the demographic variables, gender, age, marital status, frequency of use, type of income, and most used electronic equipment are first investigated. A sample of the readership is pre dominantly made up of men, aged between 36 and 45 years old, married, who read news daily, usinga netbook/notebook with income 5001-10000 real.

\section{Results}

For decision of the statistical techniques to be used, certain questions were answered in the process of conducting research. At first, the goal was to reduce dimensions and grouping on a lot of variables, making the face of measurable reality and facilitating data analysis. With the absence of the dependent variable, it is correct to seek interdependence techniques such as factor analysis. As the dimensions to be measured were not known previously, the most appropriate technique for this problem is the EFA or Factor Analysis.

In a second step, the dimensions found require assessment by the dependent variable "Intention to use". Therefore, it is valid to use dependence techniques. The dependent variable is a binary variable (nominal scale) indicates the use of Logistic Regression. This topic presents the results of AFE and RL Brazilian readers who read news on the Internet.

\subsection{Factor Analysis}

To determine the adequacy of the variables and compliance of the proposed models with the assumptions of EFA, first inspection was conducted on the correlation matrix, as Corrar Paul and Dias (2007) suggested, by scaling the variables and defining those that contribute significantly in power explanation of the model. Assumptions are considered for the acceptance variable rates of anti-image, communality, factor loadings and identification of cross-load. Each variable should contain adequate levels in all statistical tests to compose the factor model. Hair et al. (2011) define the five assumptions:

- Anti-image: Matrix of partial correlations between variables after factor analysis, and it represents the degree to which factors explain to each other the results. Reference values (must be equal to or greater than 0.5).

- Commonality: Total amount of variance that an original variable shares with all other variables included in the analysis. Reference values (must be equal or greater than 0.6).

- Load factor: Correlation between the original variables and the factors, as well as the key to understanding the nature of a particular factor. Reference values (must be equal to or greater than 0.5 in one dimension).

- Cross-load: Incidence of high factor loadings on two or more dimensions to the same variable, implying that dimensions D1 and D2 could frame the same variable. Reference values (should not have factor loadings above 0.4 in two or more dimensions).

In the assumptions assessment, the 35 variables comprising the survey instrument, 18 disapproved on one or more tests and were eliminated from the factor and consequent from the regression model step. The exclusion of each variable, the EFA was round again, since the variables are correlated, any exclusion in the factor model implies different results. The results invalidating the variables are summarized in Table 2. 
Table 2. Variables excluded for application of EFA

\begin{tabular}{|c|c|c|c|}
\hline \multicolumn{4}{|c|}{ Excluded variables in the analysis of assumptions } \\
\hline Assumption & Index D1* & Index D2* & Variable \\
\hline Cross-load & 0.493 & 0.497 & Have ways to read news on the Internet \\
\hline Commonality & 0.430 & - & Have means to read news on the Internet \\
\hline Cross-load & 0495 & 0.497 & I believe that reading news on the Internet will be a commonplace in the near future \\
\hline Cross-load & 0.516 & 0.510 & Normally, I feel the urge to read news on the Internet \\
\hline Cross-load & 0.568 & 0.585 & I've notice benefits in reading news on the Internet \\
\hline Commonality & 0.529 & - & $\begin{array}{l}\text { When I search for news on the Internet, first seek information on the websites of } \\
\text { traditional newspapers }\end{array}$ \\
\hline Factorial-load & 0.393 & - & I believe many people of my networking read news on the Internet \\
\hline Commonality & 0.507 & - & The language used by newspapers does not surprising me \\
\hline Commonality & 0.554 & - & Normally, I spend more time reading news on the Internet than in printed newspaper \\
\hline Anti-image & 0.421 & - & The layouts of news sites usually please me \\
\hline Commonality & 0.569 & - & $\begin{array}{l}\text { If the traditional newspaper offered on its website the information according to taste } \\
\text { and user interest would add much value to this website. }\end{array}$ \\
\hline Cross-load & 0.498 & 0.502 & I feel it is easy to browse news sites \\
\hline Commonality & 0.551 & - & I feel that the most efficient way to read news is on the Internet \\
\hline Factorial-load & 0.398 & - & When reading news on the Internet, I feel that I'm learning \\
\hline Cross-load & 0.579 & 0.602 & I feel in control of daily activities when you read news on the Internet \\
\hline Commonality & 0.565 & - & I'd pay to have access to certain news sites \\
\hline Cross-load & 0.478 & 0.452 & Interact on the news site is a necessity for me \\
\hline Cross-load & 0.605 & 0.478 & I cannot use all the available resources in the news pages (Ex. Videos, texts, audio etc.) \\
\hline
\end{tabular}

From the exclusion of variables, it becomes the ultimate factor model. The EFA used the method of extracting factors by principal components, by which one seeks a linear combination of the variables, so that the maximum variance is explained by this combination. The ideal it is to obtain a minimum of factors with maximum possible variance. Another advantage of the key components is that it does not require the data to be normal (Corrar, Paulo, \& Dias, 2007).

The choice of number of factors is given by eigenvalue criterion or criteria of latent root. In this criterion, each variable has zero mean and variance 1 . The eigenvalue determines the number of factors and the cumulative variance by adding factors. Factors with index below 1 have less variance and are therefore less significant

It is necessary to decide the best rotation of factors to increase the explanatory power of the factors, which generates better interpretability. A commonly chosen Varimax rotation is: the type of orthogonal rotation, i.e. perpendicular factor that keeps together, minimizing the correlation between them.

Table 3. Explanatory power of the model

\begin{tabular}{|c|c|c|c|c|c|c|}
\hline \multirow[t]{2}{*}{ Dimension } & \multicolumn{3}{|c|}{ Eigenvalues } & \multicolumn{3}{|c|}{ Explanatory power of the model of the readers } \\
\hline & Total & $\%$ Variance & Cumulative $\%$ & Total & $\%$ Variance & Cumulative \% \\
\hline 1 & 4.262 & 26.640 & 26.640 & 2.586 & 16.162 & 16.162 \\
\hline 2 & 2.439 & 15.247 & 41.887 & 2.284 & 14.274 & 30.437 \\
\hline 3 & 1.495 & 9.345 & 51.232 & 2.051 & 12.819 & 43.256 \\
\hline 4 & 1.334 & 8.338 & 59.570 & 1.668 & 10.426 & 53.681 \\
\hline 5 & 1.059 & 6.619 & 66.189 & 1.507 & 9.418 & 63.099 \\
\hline 6 & 1.006 & 6.287 & 72.476 & 1.500 & 9.377 & 72.476 \\
\hline
\end{tabular}


In the overall evaluation of the model, the Bartlett Sphericity and the Keiser-Meyer-Olkin (KMO) test were performed to test the significance of correlations between variables and adequacy of the sample model complexity. Corrar, Paulo and Dias suggest values above 0.7 for KMO and Sig. 0.000 for Bartlett. In KMO was obtained the value of 0 , and Bartlett significance of 0.000 , being considered suitable indexes.

It was used as a measure of reliability of the constructs Cronbach's alpha $(\alpha)$, "measure of reliability that ranges from 0 to 1, with values from 0.60 to 0.70 considered the lower limit of acceptability" (Hair et al., 2009, p. 100). Table 4 shows the suitability of variables and dimensions found with their factor loadings and reliability. Report any other analyses performed, including subgroup analyses and adjusted analyses, indicating those that were pre-specified and those that were exploratory (though not necessarily in the level of detail of primary analyses). Consider putting the detailed results of these analyses on the supplemental online archive. Discuss the implications, if any, of the ancillary analyses for statistical error rates.

Table 4. Dimensions in the perception of the use of readers

\begin{tabular}{|c|c|c|c|c|}
\hline Dimensions and variables & Eigenvalue & Load Factor & Variance & Alpha \\
\hline 1. Difficulty & & 4.262 & 26.640 & 0.790 \\
\hline I have little knowledge about the use of electronic equipment & 0.886 & & & \\
\hline Normally, I feel difficulty in using electronic equipment & 0.846 & & & \\
\hline $\begin{array}{l}\text { I cannot use all the available resources in the news pages (e.g.. Videos, texts, } \\
\text { audio etc.) }\end{array}$ & 0.605 & & & \\
\hline 2. External Influences & & 2.439 & 15.247 & 0.802 \\
\hline Often notice other people reading news on the Internet & 0.869 & & & \\
\hline I realize that many friends and family read news on the Internet & 0.799 & & & \\
\hline I can easily see the benefits of reading news on the Internet & 0.751 & & & \\
\hline 3. Knowledge & & 1.495 & 9.345 & 0.712 \\
\hline It is easy to navigate pages Internet News & 0.600 & & & \\
\hline Normally, access more than 10 pages when I'm reading news on the Internet & 0.799 & & & \\
\hline Know where to get the news browsing Internet & 0.736 & & & \\
\hline I am experienced regarding to surfing on the Internet & 0.544 & & & \\
\hline 4. Practicality & & 1.334 & 8.338 & 0.671 \\
\hline Reading News on the Internet is a flexible way to obtain information & 0.877 & & & \\
\hline Through the Internet, I get access to news easily & 0.771 & & & \\
\hline 5. Trust & & 1.059 & 6.619 & 0.626 \\
\hline The pages of traditional newspapers carry the most reliable news on the internet & 0.814 & & & \\
\hline $\begin{array}{l}\text { The traditional printed newspapers is the news source that has more credibility on } \\
\text { the Internet }\end{array}$ & 0.869 & & & \\
\hline 6. Effort needed & & 1.006 & 6.287 & 0.553 \\
\hline Read news on the Internet disturbs my tasks, becoming slower & 0.748 & & & \\
\hline Browse sites requires me to perform mental effort & 0.659 & & & \\
\hline Total variance explained & \multicolumn{4}{|c|}{72.476} \\
\hline
\end{tabular}

Extraction Method: Principal Component Analysis;

Rotation Method: Varimax with Kaiser Normalization;

KMO (Keiser-Meyer-Olkin): 0.731.

Bartlett 's Test of Sphericity: 5142.098 (Sig, 0.000).

According to Table 4, the dimension with the greatest explanatory power are Difficulty (Var: 26,640), followed by External Influences, Practicality, Knowledge, Trust and Effort Needed. Thus, it can be stated that the usage profile of the readers suffer more impact of the difficulties that readers have read news on the Internet. 
The adversity is composed by little knowledge about the usage of electronic equipment $(0,886)$, which creates difficulties in using electronic equipment $(0,846)$. Difficulties in using all the resources of the pages also obtained high load factor (0.605). External Influences, determined by opinions and the clear vision of the benefits of reading news also cause a strongly impact to the usage profile (Var: 15,247). Brazilian readers deem most important to eliminate the difficulties before they become experienced users. Beyond Knowledge, Practicality follows as the 4th most impactful factor. Readers deem it important the speed and the flexibility in getting news.

The 5th factor is the trust of readers. The results show that readers trust the Internet publications of traditional newspapers. Finally, the 6th impacting factor is the Effort Needed. It can be stated that the difficulties and the Effort Needed are highly related themselves, but also differ. Effort Needed requirement consists of variables that evaluate to read news on the Internet disturbs other daily activities, while Difficulties relate to lack of knowledge in the usage of electronics, used to read news on the Internet.

According to the results of the factor model, these six dimensions, based on the IDT by Rogers (1995), are possible influencing the intention to use the readers to read news on the Internet. However, to know the dimensions that can differentiate readers who intend to continue reading the news on the Internet does not have, it is necessary to ascertain the results of RL.

\subsection{Logistic Regression}

The Intention to Use is presented as a dependent variable in RL, taking as independent variables the dimensions of the usage profile. The RL allowed identifying which dimensions differ readers regarding Intention to Use and the strength of such influences. Made use of Enther method to ensure that no dimension was excluded from the model being true. The Wald (stepwise) method was also used to ensure that the exclusions followed the statistical calculations and also to facilitate communication of research results. Thus, the statistical rigor and experience of the researchers were also considered in the analysis. The stepwise introduced as factors including likelihood values equal to or less than 0.05 parameter.

Regarding the classification results show readers who intends to continue reading news on the Internet, representing $58.9 \%$ of the sample, this rate being hit by the random method of the model containing only the constant, i.e., step 0 corresponds with the moment in which no variable is already present in the model.

The model generated by Wald (stepwise) method was adjusted to 5, 6 and 9 interactions respectively. The rate of improvement or improvement (Omnibus) had a total of 44.909 after the 3rd step, according to Table 5 The inclusion of three factors in the model, the statistical -2LL decreased from 214.043in step 0 to 169.137 in step 3. Reducing total 40.909 has chi-square distribution and was significant (Sig. 0.000). Thus, each inclusion of factor was relevant to the model. The Cox test and Nagelkerke demonstrate explanatory variance of 0.393 and 0.529 respectively, and are considered appropriate for exploratory studies (Hair et al., 2011).

Table 5. Abstract model

\begin{tabular}{lcccc}
\hline Step & Likelihood log -2 & Improvement (Omnibus) & R square Cox \& Snell & R square Nagelkerke \\
\hline 1 & 194.123 & 19.92 & 0.304 & 0.410 \\
2 & 179.493 & 14.63 & 0.362 & 0.488 \\
3 & 169.137 & 10.36 & 0.393 & 0.529 \\
\hline
\end{tabular}

Improvement $=44.909$ to a Sig. $=0.000$.

The Hosmer and Lemeshow Test (Table 6) obtained in step 3 a significance of 0.929. This result can be interpreted that $\mathrm{H} 0$ was not rejected, being $\mathrm{H} 0$ : The group provided ratings are the same as observed. The three factors included in the model contributed to a great grip of the predictions to the actual values.

Table 6. Hosmer and Lemeshow test

\begin{tabular}{cccc}
\hline Step & Qui-square & df & Sig. \\
\hline 1 & 3.086 & 8 & 0.063 \\
2 & 11.090 & 8 & 0.197 \\
3 & 14.816 & 8 & 0.929 \\
\hline
\end{tabular}


The dimensions or variables found in the EFA were selected by logistic regression according to power to differentiate the group, which intends to keep reading news on the Internet from those who do not intend to continue making use of this service in the future.

In the first stage of the regression, according to Table 7, Factor 4 - Practicality is the first part of the model. In the second step, the Factor 3 - Knowledge is included, followed by Factor 2 - External Influences on the last step.

Table 7. Variables in the equation

\begin{tabular}{clcccccc}
\hline & & B & S.E. & Wald & Df & Sig. & $\operatorname{Exp}(\mathrm{B})$ \\
\hline \multirow{2}{*}{$1^{\text {st }}$ Step } & FAC4_1 & -0.803 & 0.202 & 15.833 & 1 & 0.000 & 0.448 \\
& Constant & -0.362 & 0.173 & 4.409 & 1 & 0.036 & 0.696 \\
& FAC3_1 & -0.695 & 0.193 & 12.922 & 1 & 0.000 & 0.499 \\
$2^{\text {nd }}$ Step & FAC4_1 & -0.882 & 0.217 & 16.533 & 1 & 0.000 & 0.414 \\
& Constant & -0.373 & 0.182 & 4.207 & 1 & 0.040 & 0.689 \\
& FAC2_1 & -0.619 & 0.196 & 9.984 & 1 & 0.002 & 0.539 \\
& FAC3_1 & -0.737 & 0.201 & 13.440 & 1 & 0.000 & 0.478 \\
$3^{\text {rd }}$ Step & FAC4_1 & -0.981 & 0.238 & 17.014 & 1 & 0.000 & 0.375 \\
& Constant & -0.346 & 0.190 & 3.319 & 1 & 0.068 & 0.708 \\
\hline
\end{tabular}

In Table 7, the Factor 4 shows the highest value in statistical Wald, is the factor that has the greatest impact on inequality (for prediction) in changing a unit while keeping the other constant. Negative beta values indicate that factors 2, 3 e 4 has negative relation with low intention to use. The dependent variable is dichotomous, being 0 high intention to use and 1 - low intention to use. In this way, external influences (Factor 2), knowledge (Factor 3 ) and Practicality (Factor 4) influence positively the intention to read newspapers on the Internet by users.

On the Table of General Classification (Table 8) the predictive ability of the regression model is shown, reaching $76.6 \%$. The percentage of correctness of the model exceeded the overall percentage by method of chance $(58.9 \%)$ at $17.7 \%$, indicating that the generated model is feasible and reproducible. At each stage, the overall percentage increase $(65.8->70.9->76.6)$, indicating that it made sense to insert more factors at each stage. The hit rate of those who intend to keep reading news on the Internet also obtained increasing values (76 - > 78 - > 82) respectively.

Table 8. General classification

\begin{tabular}{|c|c|c|c|c|c|}
\hline & & & \multicolumn{3}{|c|}{ Expected } \\
\hline & \multicolumn{2}{|c|}{ Observed } & \multicolumn{2}{|c|}{ Intention to use } & \multirow[t]{2}{*}{ Correct Percentage } \\
\hline & & & 0 - High & 1 - Low & \\
\hline \multirow{3}{*}{ Step 1} & & 0 & 76 & 17 & 81.7 \\
\hline & Intention to use & 1,00 & 37 & 28 & 43.1 \\
\hline & Global percentas & & & & 65.8 \\
\hline \multirow{3}{*}{ Step 2} & & 0 & 78 & 15 & 83.9 \\
\hline & Intention to use & 1,00 & 31 & 34 & 52.3 \\
\hline & Global percentag & & & & 70.9 \\
\hline \multirow{3}{*}{ Step 3} & Intention to use & 0 & 82 & 11 & 88.2 \\
\hline & HIt & 1,00 & 26 & 39 & 60.0 \\
\hline & Global Percenta & & & & 76.6 \\
\hline
\end{tabular}

a. Cutoff value is 0.500 . 


\section{Discussion and Final Remarks}

According to the perception of readers nationwide, the assessment of reading news online is positive. The results of factor and regression reveal that the Practicality is the major contributing factor to differentiate the variable of intention to use, which is a critical factor that Brazilian newspapers companies should direct efforts linked to management and strategy.

The regression model for the perception of readers suggests that practicality, knowledge and External Influences are the differentiating factors of the intention of readers to continue to read newspapers on the Internet. Knowledge and Practicality are compatible with the need of the readers about its easy usability of the reading system. It is also compatible with the view of journalists in relation to the language used in websites and layout, being crucial to the continued increase readership.

Thus, the main contribution of this study was to elucidate the factors that must be managed more diligently, i.e., is critical to maintaining the innovative public, to intend to continue reading news on the Internet and being critical factors to influence the public that has no intention of use to become regular users of newspaper companies. In general, the study is inconclusive in regard to the claim that the Internet is a substitute or complement to the traditional media. Jerit and Gaskins (2013), argue that similar surveys suggest no conclusive answers, just consists of the intensification in the migration process.

However, this study allows us to go beyond the said, finding the perception of readers and journalists to prioritize efforts and strategic market for digital media at the expense of the printed newspaper. Thus, newspaper companies must adapt to the new market, using multiple platforms and resources and seek to meet both the demand for newspapers such as the growing demand from users of digital media (Olmsted \& Zerba, 2013).

The main limitation of this study is that the research was restricted to the base of Internet users. The search results are subject to some limitations, the main refers to the use of the Internet as the sole source of research. A more comprehensive version could enlarge the interviews focused on subscribers of traditional print newspapers, so the responses of the study would have greater amplitude.

It is suggested for future research that the study is also applied with the public who are not Internet users. The differentiating factors of the intended use could be distinct from those found for the public that uses the Internet. It is also suggested that other multivariate analysis techniques are used in this field of study, which still lacks studies that measure behavioral aspects of newspaper reader by the Internet.

\section{References}

Aitamurto, T., \& Lewis, S. C. (2012). Open innovation in digital journalism: Examining the impact of open APIs at four new organizations. New Media \& Society, 15(2), 314-331. http://dx.doi.org/10.1177/14614448812450682

Anj - Associação Nacional Dos Jornais. (2013). Retrieved 9 January, 2014 from http://www.anj.org.br

Black, N. J. et al. (2001). The Adoption of Internet Financial Services: a qualitative study. International Journal of Retail \& Distribution Management, 29(8), 390-398. http://dx.doi.org/10.1108/09590550110397033

Cacciatore, M. A., Anderson, A. A., Doo-Hun, C., Brossard, D., Scheufele, D. A., Xuan, L., Ladwig, P. J., Xenos, M., \& Dudo, A. (2012). Coverage of emerging technologies: A comparison between print and online media. New Media \& Society, 14(6), 1039-1059. http://dx.doi.org/10.1177/1461444812439061

Carr, J. V. H. (2013). Technology adoption and diffusion. Retrieved 27 June, 2014 from http://tlc.nlm.nih.gov/resources/publications/sourcebook/adoptiondiffusion.html

Chung, C. J., Nam, Y., \& Stefanone, M. A. (2012). Exploring online news credibility: The relative influence of traditional and technological factors. Journal of Computer-mediated Communication, (17), 171-186. http://dx.doi.org/10.1111/j.1083-6101.2011.01565.x

Chyi, H. I., \& Angela, M. L. (2012). Theorizing online news consumption: a structural model linking preference, use, and paying intent. $13^{\text {th }}$ International Symposium on Online Journalism. Austin, TX.

Chyi, H. I., \& Chang, H. C. (2009). Examining the use of and preference for online news in the context of intermedia competition. In L. Leung, A. Fung, \& P. Lee (Eds.), Embedding into our lives: New opportunities and challenges of the Internet (pp. 101-123). Hong Kong: Chinese University Press.

Chyi, H. I., \& Lee, A. M. (2013). Will the internet disrupt? A reality check on format preference for traditional and digital content across five media. In World Media Economics and Management Conference, 10, Thessaloniki, Greece. 
Corrar, L. J., Paulo, E., \& Dias, J. F. (2007). Análise multivariada de dados: Para os cursos de administração, ciências contábeis e economia. São Paulo: Atlas.

Cronin, M. (1996). The Internet as a Competitive Business Resource. In M. Cronin (Ed.), The internet strategy handbook. Boston: Harvard Business School Press.

Dotson, D. M., Jacobson, S. K., Kaid, L. L., \& Carlton, J. S. (2012). Media coverate of climate change in Chile: A content analysis of conservative and liberal newspapers. Environmental communication, 6(1), 64-81.

Fávero, L. P. et al. (2009). Análise de dados: modelagem multivariada para tomada de decisões. Rio de Janeiro: Elsevier.

Franklin, B. (2013). Digital journalism - editorial. Digital Journalism, 1(1), 1-5. http://dx.doi.org/10.1080/21670811.2012.740264

Gascoyne, R., \& Ozcubucku, K. (1997). Corporate internet planning guide. New York: Van, Nostrand and Reinhold.

Gaskins, B., \& Jerit, J. (2013). Internet news: Is it a replacement for traditional media outlets? The International Journal of Press/Politics, 17(190).

Gil, A. C. (2002). Técnicas de pesquisa em economia e elaboração de monografias (4th ed.). São Paulo: Atlas.

Gimpel, G., \& Westerman, G. (2012). Shaping the future: Seven enduring principles for fast-changing industries.

Hair, J. et al. (2011). Análise multivariada de dados (6th ed.). Porto Alegre: Bookman.

Hair, J. F. et al. (2010). Fundamentos de métodos de pesquisa em administração. São Paulo: Arkmed/Bookman.

Hennschen, H., \& Andersen, M. (2012). An innovator's guidance to cost efficient diffusion. Communication Project.

Instituto Brasileiro de Opinião Pública e Estatística - IBOPE. Introdução. (2013). Retrieved from http://www.mmassessoria.com/index.php/artigos/87-negocios/173-ibope-com-nova-contagem-numero-de-in ternautas-brasileiros-passa-de-94-milhoes

IVC. (n. d). Instituto verificador de circulação. Retrieved 12 June, 2014 from http://www.ivc.org.br

Jabri, I. (2012). Mobile banking adoption: application of diffusion of innovation theory. Journal of Eletronic Commerce Research, 13(4).

Jacobsen, D. M. (1998). Adoption patterns of faculty who integrate computer technology for teaching and learning in higher education. Proceedings of the Ed-Media and Ed-Telecom 98: World Conference on Educational Multimedia and Hypermedia \& World Conference on Educational Telecommunications. Freiburg, Germany June 20-25, 1998a. Retrieved 05 June, 2014 from http://www.acs.ucalgary.ca/ dmjacobs/phd/phdresults.html

Jenkins, H. (2008). Cultura da convergência. São Paulo: Aleph.

Joo-Young, J., Wan-Ying, L., \& Yong-Chan, K. (2012). The dynamic relationship between East Asian adolescents' use of the Internet and their use of other media. New Media \& Society, 14(6), 969-986. http://dx.doi.org/10.1177/1461444812437516

Kaufhold, K. (2010). Journalists show unified optimism about young adults' news consumption. Newspaper Research Journal, 31(2), 63-68.

Lee, K. C., \& Chung, N. (2009). Understanding factors affecting trust in and satisfaction with mobile banking in Korea: A modified DeLone and McLean's model perspective. Interacting with Computers, 21(5/6), 385-392. http://dx.doi.org/10.1016/j.intcom.2009.06.004

Mayr, S. et al. (2007). A short tutorial of G*Power. Tutorials in Quantitative Methods for Psychology, 3(2), $51-59$.

Means, B. et al. (1993). Using technology to support education reform. Washington, DC. US Department of Education. Retrieved from http://www.ed.gov/pubs/EdReformStudies/TechReforms/title.html

Meyer, P. (2007). Os jornais podem desaparecer? São Paulo: Contexto.

NAA - Newspaper Asssociation of America. (2013). Retrieved 20 Oct., 2013 from http://www.naa.org

Nielsen, J., \& Tahir, M. (2012). Home Page: 50 websites desconstruídos. Rio de Janeiro: Campus.

Olmsted, S. C., Rim, H., \& Zerba, A. (2013). Mobile news adoption among young adults: Examining the roles of 
perceptions, news, consumption, and media usage. Journalism \& Mass Commnication Quarterly, 90(126).

Orihuela, J. L. (2003). eCommunication: The 10 paradigms of media in the digital age. IIA20 COST Conference.

Peng, F. Y., Tham, N. I., \& Xiaoming, H. (1999). Trends in online newspapers: A look at the US web. Newspaper Research Journal, 20(2), 52-63.

Rogers, E. (2003). Diffusion of Innovations (5th ed.). New York: Free Press.

Rogers, E. M. (1983). Diffusion of innovations (3rd ed.). New York: Free Press.

Rogers, E. M. (1995). Diffusion of innovations. New York: Free Press.

Samara, B. S., \& Barros, J. C. (2002). Pesquisa de Marketing: conceitos e metodologia (3rd ed.). São Paulo: Prentice Hall.

Surry, D. W. (1997). Diffusion theory and instructional technology. Paper presented at the Annual Conference of the Association for Educational Communications and Technology (AECT), Albuquerque, New Mexico, February 12-15. Retrieved from http://www.gsu.edu/ wwwitr/docs/diffusion/index.html

\section{Copyrights}

Copyright for this article is retained by the author(s), with first publication rights granted to the journal.

This is an open-access article distributed under the terms and conditions of the Creative Commons Attribution license (http://creativecommons.org/licenses/by/3.0/). 